\title{
EDUCAÇÃO MUSICAL E ALTAS HABILIDADES: COMENTÁRIOS E APONTAMENTOS
}

\section{MUSICAL EDUCATION AND HIGH SKILLS: COMMENTS AND NOTES}

\author{
Ana Paula Revelini ${ }^{1}$
}

Andressa Schiavone Pereira Aquaroni Vieira ${ }^{2}$

\begin{abstract}
RESUMO: O presente artigo visa problematizar como as ações do professor, que recorre à educação musical, interferem de maneira significativa no desenvolvimento dos processos de ensino e aprendizagem de alunos que possuem altas habilidades. A pesquisa apresenta o conceito e as políticas públicas que versam sobre o assunto. Os apontamentos possibilitam refletir sobre as necessidades educacionais de alunos com altas habilidades, além de conhecer como os professores podem lidar com este aspecto situacional, conhecendo métodos e considerando o cotidiano destes alunos com as altas habilidades. Com isso, concluise que o professor precisa ser flexível, estar em constante atualização quanto a metodologias, pesquisas e estudos, bem como sempre buscar novas estratégias, para proporcionar um bom desenvolvimento para seus alunos.
\end{abstract}

Palavras-chave: Altas Habilidades. Aprendizagem Musical. Educação Musical.

ABSTRACT: This article aims to discuss how the actions of the teacher, who uses music education, significantly interfere in the development of the teaching and learning processes of students who have high skills. The research presents the concept and public policies that deal with the subject. The notes make it possible to reflect on the educational needs of students with high skills, in addition to knowing how teachers can deal with this situational aspect, knowing methods and considering the daily lives of these students with high skills. With that, it is concluded that the teacher needs to be flexible, be constantly updated as to methodologies, research and studies, as well as always looking for new strategies, to provide a good development for his students.

Keywords: High Skills. Musical Learning. Music Education.

\section{INTRODUÇÃO}

A partir do questionamento de um aluno com altas habilidades durante uma aula sobre acústica, Piekarski (2016) aborda as maneiras pelas quais discentes com essa condição, pensam, sentem e têm curiosidade em como a música e seus elementos se complementam.

\footnotetext{
I Graduada em Pedagogia pela Faculdade de Ciências de Wenceslau Braz - FACIBRA e Graduada em Direito pela Fundação Assis Gurgacz - FAG. Especialista em Psicopedagogia Clínica, Institucional e Hospitalar pela Faculdade de Tecnologia de Curitiba - FATEC. Mestranda em Gestão do Conhecimento nas Organizações pelo Centro Universitário Cesumar - UniCesumar. E-mail: anapaularevelini@gmail.com

2 Graduada em Pedagogia pela Unicesumar (2006). Especialista em Docência no Ensino Superior: Tecnologias educacionais e inovação. Especialista em Docência no Ensino Superior. Especialista em Atendimento Educacional Especializado. Especialista em EAD e as Tecnologias Educacionais. Especialista em Psicopedagogia Institucional. 
Alicerçadas nas leituras dos trabalhos de Piekarski (2016), vários questionamentos se originaram, dentre eles, como os professores lidam com alunos com altas habilidades no contexto musical? Como ocorre o incentivo musical de alunos que despertam altas habilidades em música? Esse incentivo realmente existe e é pensado no processo de aprendizagem musical? Os professores estão prontos a atender esses alunos?

Pensando nestas questões, a presente pesquisa tem por objetivo principal investigar a ação do professor no desenvolvimento de ensino e aprendizagem de alunos com altas habilidades na modalidade música e como essa ação influencia no desenvolvimento dessas crianças.

Diante de tal objetivo, o trabalho pretende entender e discutir como ocorre a aprendizagem musical do aluno que possui altas habilidades. Além de conhecer a metodologia utilizada por um professor da disciplina de música que atua na educação desses alunos. Assim como, o seu preparo para tais aulas e discutir a importância de atender as necessidades específicas de aprendizagem de um aluno com altas habilidades musicais.

Para dar conta do objetivo proposto, o trabalho utiliza como metodologia a pesquisa bibliográfica em fontes reconhecidas e consideradas seguras. A investigação qualitativa, segundo Bogdan e Biklen (1994), apesar de possuir uma longa e rica tradição, foi reconhecida no campo da educação a partir dos anos 1980, mas vem incidindo sobre diversos aspectos da vida educativa há tempos. Bogdan e Biklen (1994) e Godoy (1995) compartilham do mesmo pensamento, de que esse tipo de trabalho possui cinco características essenciais, sendo elas: a fonte direta de dados é o ambiente natural; a investigação qualitativa é descritiva; os investigadores interessam-se mais pelo processo do que pelos resultados; os investigadores tendem a analisar os seus dados de forma indutiva; o significado é de grande importância na abordagem qualitativa.

Assim, realizar uma pesquisa com abordagem qualitativa requer do pesquisador, clareza quanto à necessidade de se aprofundar em estudos que permitam diagnosticar profundamente a realidade a ser pesquisada. Além disso, está dividido de maneira tal que o leitor possa ter uma boa compreensão, sendo a primeira parte uma discussão acerca do que são as altas habilidades e, posteriormente, abordando sobre altas habilidades e educação musical.

I Altas habilidades: concepções e legislação

Segundo documento oficial do Ministério da Educação e Cultura, "Altas Habilidades", também conhecido como "Superdotação", pode ser definido como crianças:

[...] que apresentam notável desempenho e elevada potencialidade em qualquer dos seguintes aspectos, isolados ou combinados: capacidade intelectual geral, aptidão acadêmica específica, pensamento criador ou produtivo, capacidade de liderança, talento especial para as artes e capacidade psicomotora. (BRASIL, 2006, p. 26) 
Ainda, segundo o Ministério da Educação, as altas habilidades se caracterizam pela “[...] elevada potencialidade de aptidões, talentos e habilidades, evidenciadas no alto desempenho das diversas áreas de atividade do educando e/ou a ser evidenciada no desenvolvimento da criança” (BRASIL, 2006, p. I2).

Assim, a criança que apresenta maior facilidade nas atividades escolares, como, por exemplo, raciocínio matemático ágil, presteza nas atividades de língua portuguesa, entre outros, que se sobressaem das demais crianças e ultrapassa o nível de aprendizagem e desenvolvimento cognitivo esperado pela idade e/ou série letiva, pode ser considerada como tendo altas habilidades. Porém, não se pode basear o diagnóstico apenas nesses fatores, sendo necessária a intervenção de profissionais habilitados na área da educação, psicologia e medicina, e, para tal, uma vez que a criança pode não apresentar nenhum dos aspectos apresentados também.

Sobre isso, Souza (2013) enfatiza que nem todos que possuem altas habilidades apresentam todas essas características e habilidades e, quando as possuem, não as apresentam necessariamente em simultaneidade. Dependendo das circunstâncias em que as pessoas vivem, algumas características podem ser evidenciadas, enquanto outras podem ficar camufladas.

Durante muitos anos, as altas habilidades nos indivíduos foram mensuradas por testes lógicos de QI (Quociente Intelectual). Estudos apontam que, por muito tempo, a inteligência era vista como um conceito unidimensional, medido por um teste de QI que, segundo Negrini e Freitas (2008), vem sofrendo críticas por medirem apenas as inteligências lógico-matemática, linguística e espacial do aluno, sem levar em consideração as demais capacidades e a realidade próprias de cada tipo de habilidade humana.

No que diz respeito à isso, diversas medidas estão no campo da educação de modo a intervirem positivamente na aprendizagem de superdotados, tais como "provas psicológicas estandardizadas; provas acadêmicas de incidência curricular, escalas para pais e professores; redação de ensaios breves; inventários de criatividade; entrevistas individuais [...]” (POCINHO, 2009, p. 8).

Quanto à avaliação clínica, a autora sugere que seja feita por uma equipe e que esta equipe, seja multidisciplinar: pedagogo, psicólogo, especialista em altas habilidades, pois são eles quem podem conceder o "laudo de superdotação". Além destas questões, existem outras medidas que podem ser tomadas, como inclusão de questionários, inventários, autoavaliações, testes psicométricos de inteligência e aptidões, entre outros. Contudo, entre os métodos, o mais utilizado segundo relato de Pocinho (2009), reporta-se às escalas de Wechsler, nomeado como "Wechsler Intelligence Scale for Children (WISC) e a WPPSI, seguidas da Stanford-Binet Intelligence Scale".

Ao referir-se a alunos que possuem altas habilidades no contexto escolar brasileiro, seu 
atendimento está pautado a partir dos princípios que regem documentos internacionais, como, por exemplo, a Declaração de Salamanca ${ }^{3}$ e a Declaração Mundial de Educação para Todos da $\mathrm{UNESCO}^{4}$. No que diz respeito este tema à legislação Brasileira, existem documentos que amparam os direitos desses alunos, como a Constituição da República Federativa do Brasil (CF, 1988), o Estatuto da Criança e do Adolescente (ECA - Lei 8.069/9o) e a Lei de Diretrizes e Bases da Educação Nacional (LDBEN - Lei 9394/96).

Além destes documentos legais, pode-se mencionar outros documentos legais que são normatizações desenvolvidas pelo Plano Nacional de Educação (PNE) e as Diretrizes Nacionais para Educação Especial na Educação Básica (Parecer 17/20oI, aprovado em 03/o7/200I), o que ver-se-á a seguir.

1.2 Altas habilidades e as leis governamentais

Ao referir-se sobre legislação relacionada a altas habilidades, é necessário mencionar os artigos 58 e 59 da Lei De Diretrizes e Bases da Educação Nacional (BRASIL,1996), pois definem e explicitam o dever da escola e de seus profissionais em estar devidamente preparados para atender esses alunos e assumir uma postura primordial frente a essa realidade:

Art. 58. Entende-se por educação especial, para os efeitos desta Lei, a modalidade de educação escolar oferecida preferencialmente na rede regular de ensino, para educandos com deficiência, transtornos globais do desenvolvimento e altas habilidades ou superdotação.

Art. 59. Os sistemas de ensino assegurarão aos educandos com necessidades especiais:

I - currículos, métodos, técnicas, recursos educativos e organização específicos, para atender às suas necessidades;

II - terminalidade específica [...]

III - professores com especialização [...]

IV - educação especial para o trabalho, [...] (BRASIL, 1996, p. 25)

Analisando a Declaração de Salamanca (1994), percebe-se que esta declaração demanda sobre princípios, políticas e práticas na área das necessidades educativas especiais, em que o Estado assegura a educação de pessoas com deficiência, fazendo-a parte do sistema educacional. Tal declaração se encontra no documento das Nações Unidas e envolvem governos, grupos de

\footnotetext{
${ }_{3}^{3}$ Documento elaborado na Conferência Mundial sobre Educação Especial, em Salamanca, na Espanha, em 1994, com o objetivo de fornecer diretrizes básicas para a formulação e reforma de políticas e sistemas educacionais de acordo com o movimento de inclusão social. Disponível em: 〈http://www.educabrasil.com.br/declaracao-de-salamanca/〉. Acesso em: 3 de out. 2019.
}

${ }^{4}$ A Conferência Mundial sobre Educação para Todos, realizada de 5 a 9 de março de 1990, organizada pela UNESCO, ocorreu em Jomtien, na Tailândia. Durante a conferência, foi estipulada a Declaração Mundial de Educação para Todos, com o intuito de impulsionar os esforços para oferecer a educação adequada para toda a população em seus diferentes níveis de ensino. Disponível em: hhttp://educacao.fabercastell.com.br/professores/trocando-ideias/declaracao-mundial-sobre-educacao-para-todos-satisfacaodas-necessidades-basicas-de-aprendizagem/>. Acesso em: 3 de out. 2019. 
advocacia, comunidades, pais e organização de pessoas com deficiência para buscar a melhoria da educação.

Nessa Conferência Mundial, em 1994, culminou-se nas "Regras Padrões sobre Equalização de Oportunidades para Pessoas com Deficiências", e foi declarado que a criança tem direitos muito bem definidos, assim como os governos têm o dever de garantir tais direitos, como pode ser observado no excerto abaixo:

$$
\begin{aligned}
& \text { [...] - toda criança tem direito fundamental à educação[...] } \\
& \text { - toda criança possui características, interesses, habilidades e necessidades de } \\
& \text { aprendizagem que são únicas, } \\
& \text { - sistemas educacionais deveriam ser designados e programas educacionais } \\
& \text { deveriam ser implementados no sentido de se levar em conta a vasta } \\
& \text { diversidade de tais características e necessidades [...] } \\
& \text { 3. Nós congregamos todos os governos e demandamos que eles: } \\
& \text { - atribuam a mais alta prioridade política e financeira ao aprimoramento de } \\
& \text { seus sistemas educacionais [...] } \\
& \text { - adotem o princípio de educação inclusiva [...] } \\
& \text { - desenvolvam projetos de demonstração e encorajem intercâmbios [...] Entre } \\
& \text { outros (DECLARAÇÃO DE SALAMANCA, I994, p. I). }
\end{aligned}
$$

Em complemento à Declaração de Salamanca, a LDB/96 afirma que, além dos deveres do Estado, a escola e seus profissionais devem estar devidamente preparados para atender esses alunos e assumir uma postura primordial frente a essa realidade em seus aspectos curriculares. (BRASIL, 1996)

Pensando no contexto da educação musical, isso significa que, mesmo que o aluno não tenha altas habilidades em música, a escola deve proporcionar condições para que o aluno se desenvolva, buscando uma educação qualificada aos seus interesses pessoais.

I.3 Altas habilidades e educação musical

Quando se menciona altas habilidades e educação musical, Ogando (2015) afirma ser muito difícil encontrar trabalhos com tal temática e que, até então, não existe artigo que utiliza as terminologias altas habilidades e/ou superdotação nos títulos dos periódicos e revistas de educação musical. De fato, isso foi evidenciado em uma pesquisa necessária e aprofundado nos periódicos da área dos últimos i6 anos, tais como Anais de eventos, (ABEM, SIMPOM e ANPPOM) revistas (OPUS E ABEM) e periódicos da CAPES para encontrar literatura sobre esse tema.

Piekarski (2016) também trabalhou com a ampliação do repertório artístico e musical dos alunos, oportunizando vivências por meio de apreciação, possibilitando aos estudantes tocar e cantar com conhecimento técnico e teórico, entre outras coisas.

Hong e Page (2004) afirmam que estudantes com altas habilidades foram mais estratégicos no estudo realizado com ilustrações, ou seja, a aprendizagem com materiais didáticos 
ilustrados podem ser mais prontamente atendidos por estudantes com altas habilidades, alcançando melhores resultados. São propostas iniciais, mas que revelam a necessidade de se pensar em estratégias e formas de desenvolver uma aprendizagem musical contemplando outras possibilidades de interação com estes alunos.

Conforme as leituras realizadas, pode-se perceber a importância das altas habilidades no contexto educacional, uma vez que está enquadrada como educação especial, com legislação e normativas que asseguram a educação diferenciada, além de profissionais capacitados adequadamente para atender tais crianças. Também pode-se perceber o quanto a música e a educação musical são imprescindíveis para que o desenvolvimento dessas crianças ocorra de maneira suave e diferenciada, sem ser excludente.

\section{Considerações finais}

No início da pesquisa deparou-se com a dificuldade de se encontrar estudos sobre o ensino e aprendizagem em música de alunos com altas habilidades/superdotação. Há pouca literatura sobre o tema, deixando clara a necessidade de aprofundamento de estudos na área de educação musical. Apesar de estar previsto em lei que todos os alunos com altas habilidades precisam ser atendidos em suas necessidades, o que ocorre, é a falta de visibilidade que esse tema tem, por sua complexidade.

Por meio da pesquisa foi possível perceber que ter altas habilidades não significa ter sucesso em todas as áreas do conhecimento, que são mais comuns as aptidões em algumas áreas, como, por exemplo, a área de exatas. Assim como ter altas habilidades em música não significa ter ouvido absoluto, podendo ou não acontecer. O professor precisa atender as necessidades dos alunos, estimular as suas capacidades a partir do seu interesse, para que assim se atinja o objetivo de proporcionar ao aluno o conhecimento que ele necessita.

Pode-se verificar que ainda existe um grande de número de alunos que apresentam necessidades especiais, mas que não foi diagnosticado, isso pode estar ligado ao alto custo para diagnosticar as altas habilidades. No caso da escola, o diagnóstico se faz importante, para que haja o atendimento necessário para o aluno com altas habilidades, evitando que ele possa desenvolver um mau comportamento devido às suas necessidades de aprendizagem. Em relação à música, o diagnóstico não é garantia de sucesso, bem como uma pessoa não diagnosticada pode obter sucesso no que faz.

Pensando nos objetivos que foram propostos para essa pesquisa, conclui-se que a ação do professor diante das altas habilidades está diretamente ligada ao desenvolvimento escolar do aluno. Há muitas propostas que não saem do papel, muitas leis que preveem a importância de se atender às necessidades educacionais de um aluno com altas habilidades no contexto escolar, mas 
infelizmente há pouca ação propriamente dita. A desigualdade entre proposta e ação fica muito nítida ao se procurar cursos de especialização na área de altas habilidades ou na grade curricular de cursos de formação. É sabido que esse ainda é um tema emergente no Brasil, mas que tem resultados sérios quando não é diagnosticado.

Diante das informações adquiridas no processo de escrita dessa pesquisa, conclui-se que as altas habilidades necessitam de um novo olhar, principalmente quando se trata de música. Conhecer o potencial dos alunos, sejam eles com altas habilidades ou não, sempre é importante para um bom exercício profissional.

\section{REFERÊNCIAS}

BRASIL. Lex: Constituição da República Federativa do Brasil de 1988. Disponível em: 〈http://www.planalto.gov.br/ccivil_03/constituicao/constitui\% $\mathrm{C}_{3} \% \mathrm{~A}$ 7ao.htm>. Acesso em: 02 out. 2019.

BRASIL. Lei n. 8.069, de 13 de julho de 1990. Dispõe sobre o Estatuto da Criança e do Adolescente e dá outras providências. Lex: Estatuto da Criança e do Adolescente. Disponível em: 〈http://www.planalto.gov.br/ccivil_03/Leis/L8069.htm〉. Acesso em or out. 2ol9.

BRASIL. Diretrizes Nacionais para a Educação Especial na Educação Básica. Resolução CNE/CEB no. o2, de II de setembro de 200I. Ministério da Educação, 20ora. Disponível em: <http://portal.mec.gov.br/cne/arquivos/pdf/CEBozor.pdf〉. Acesso: or out. 2019.

BRASIL. LEI n. ${ }^{\circ}$ 9394, de 20 de dezembro de 1996. Estabelece as diretrizes e bases da educação nacional. Disponível em: 〈http://www.planalto.gov.br >. Acesso: 29 set. 2019.

BRASIL. Ministério da Educação. Educação infantil: saberes e práticas da inclusão: altas habilidade/superdotação. [4. ed.] / elaboração Denise de Souza Fleith. Brasília: MEC, Secretaria de Educação Especial, 2006.

BRASIL. MINISTÉRIO DA EDUCAÇÃO E CULTURA. SECRETARIA DE EDUCAÇÃO ESPECIAL. Documento orientador execução da ação dos núcleos de atividades de altas habilidades/superdotação. Brasília: MEC, 2006.

DECLARAÇÃ O DE SALAMANCA: Sobre Princípios, Políticas e Práticas na Área das Necessidades Educativas Especiais. Salamanca-Espanha, 1994.

NEGRINI, Tatiane; FREITAS, Soraia Napoleão. A identificação e a inclusão de alunos com características de altas habilidades/superdotação: discussões pertinentes. Revista “Educação Especial” n. 32, p. 273-284. Santa Maria, 2008.

OGANDO, Marcia Gabriela Correia. A garantia dos direitos de educandos com altas habilidades ou superdotação na Educação Básica: considerações sobre os desafios no contexto de aulas de Música. Anais do XXII Congresso da ABEM. Natal, 2015. 
PIEKARSKI, Teresa Cristina Trozzolini. Produção Sonora e Musical: uma experiência com crianças com altas habilidades e superdotação. Universidade Federal do Paraná. Secretaria Municipal da Educação de Curitiba. XVII Encontro Regional Sul da ABEM. Curitiba, 2016.

POCINHO, M. Superdotação: conceitos e modelos de diagnóstico e intervenção psicoeducativa. Revista Brasileira de Educação Especial. v. I5, n. I, Jan./Abr., 2009. Disponível em: 〈http://www.scielo.br/pdf/rbee/visnI/o2.pdf 〉. Acessado em: is set 2019.

Resolução das Nações Unidas adotada em Assembléia Geral. Disponível em: $\langle$ http://portal.mec.gov.br/seesp/arquivos/pdf/salamanca.pdf 〉. Acesso em I7 set. 2019.

SOUZA, Vanessa Stefani de. Altas Habilidades E Superdotação: Uma reflexão sobre o tema. Monografia De Especialização. Universidade Tecnológica Federal do Paraná. Medianeira, 2013. 